\title{
Beliefs About the Economic Impact of Immigration
}

\author{
JAMES TREMEWAN
}




\title{
Beliefs About the Economic Impact of Immigration
}

\author{
James Tremewan
}

March 4, 2009

\begin{abstract}
The public's beliefs about the economic impact of immigration on host nations' economies is significantly more negative than both the beliefs of economists, and what much of the empirical evidence would suggest. In an attempt to explain this disparity, and the wide range of beliefs about what should largely be a matter of fact, I develop a simple model of belief formation based on the concept of motivated reasoning: when coming to a conclusion people are influenced by the desire to come to a particular conclusion (a "directional goal") and by the desire for their conclusion to be justified by evidence (an "accuracy goal"). This gives agents an incentive to manipulate their beliefs. The model yields several testable hypotheses: positive beliefs about the economic impact of immigrants should be negatively associated with a preference for living in an ethnically homogeneous society; the effect of education depends crucially on the aforementioned preference; finally, beliefs should reflect the probability of receiving supporting evidence. An empirical analysis using the European Social Survey 2002/2003 data finds support for all three hypotheses.
\end{abstract}

JEL classification: D83, J61

Keywords: Motivated Reasoning, Behavioural Economics

For comments and discussion I thank Roberta Dessi, Guido Freibel, Thierry Magnac, Javier Ortega, and Jean Tirole. 
Despite the popular belief that immigrants have a large adverse impact on the wages and employment opportunities of the native-born population, the literature on this question does not provide much support for this conclusion.

Freidberg and Hunt (1995)

Beggars can't be choosers, you deceive yourself as best you can.

Péter Esterházy (2005), Celestial Harmonies

\section{Introduction}

The economic impact of immigration on host nations' economies is a much studied subject. As with many economic issues, there is a range of opinions amongst economists as to whether immigrants improve or reduce the economic well-being of natives, however the distribution of these opinions is strikingly different from the beliefs of the public. The difference in beliefs between economists and the public is highly significant: in the Survey of Americans and Economists on the Economy, more than three quarters of economists said that excessive immigration was 'not a reason at all' for problems in the economy, whereas a large majority of non-economists regarded it as either of minor or major importance. ${ }^{1}$

There is a large body of empirical evidence suggesting that immigration is economically beneficial. More specifically, that immigration boosts growth, ${ }^{2}$ increases innovation and creation of new businesses, ${ }^{3}$ has little or no impact on wages or employment of natives, ${ }^{4}$ and that the average fiscal contribution of immigrants is positive and, in the cases of New Zealand and the United Kingdom, greater than the average contribution of natives. ${ }^{5}$ On the other hand, in the European Social Survey 2002/2003, only 37 percent of respondents believed that immigration is good for the economy, while only 20 percent believed that

\footnotetext{
${ }^{1}$ Caplan (2002)

${ }^{2}$ Barro and Sala-i-Martin (1992)

${ }^{3}$ Hunt and Gauthier-Loiselle (2009)

${ }^{4}$ Blanchflower et al. (2007); Freidberg and Hunt (1995). For a dissenting opinion see Borjas (2003)

${ }^{5}$ Gott and Johnston (2002); Nana and Williams (1999)
} 
immigrants contribute as much in taxes as they consume in health and welfare services.

To begin to explain this disparity we need to develop a model of belief formation. This paper presents a simple model of belief formation based on the concept of motivated reasoning: when coming to a conclusion, people are influenced by the desire to come to a particular conclusion, and by the desire for their conclusion to be justified by evidence. Following the terminology of Kunda (1990), the former is a directional goal, the latter an accuracy goal. This combination of preferences gives agents an incentive to manipulate their beliefs.

The model yields several testable hypotheses: beliefs that run counter to the desired conclusion are less likely to be held by people with stronger directional goals; the effect of the accuracy goal depends crucially on the relative strength of the directional goal; finally, beliefs should reflect the probability of receiving supporting evidence.

The implications of this general model are tested for the specific example of beliefs about the economic impact of immigration: using data on four different economic beliefs, and proxies for the strength of directional and accuracy goals from the European Social Survey, probit regressions find support for all three hypotheses. Beliefs about the economic impact of immigrants are strongly correlated with a number of both attitudinal and economic variables. These results suggest that exisiting empirical work on determinants of attitudes towards immigration needs to be reconsidered.

Motivated reasoning is a well documented psychological phenomenon. A number of studies exist showing a change in reasoning and evaluation of evidence when directional and accuracy goals are present, many of which are summarized in Kunda (1990), who states:

“... people motivated to arrive at a particular conclusion attempt to be rational and to construct a justification of their desired conclusion that would persuade a dispassionate observer.... In other words, they maintain an "illusion of objectivity." To this end, they 
search memory for those beliefs that could support their desired conclusion."

One experimental example is Taber and Lodge (2006). This paper looks at how the evaluation of arguments about gun control and affirmative action depends on the strength of prior attitudes (a measure of a directional goal) and political sophistication (a measure of an accuracy goal). They found that participants in their experiment spent more time considering, and were more likely disregard arguments that opposed a strong prior attitude as compared to arguments that were in agreement. They also found that this effect is greater for those who are more politically sophisticated.

In the context of this paper, the directional goal is to oppose immigration because of an inherent preference against the presence of immigrants in the country. This preference could arise from simply discomfort at being exposed to foreign cultures, a perceived threat to a strongly held idea of national identy, or xenophobia with evolutionary roots. ${ }^{6}$ A distrust of foreigners is ubiquitous amongst human (and animal) societies ${ }^{7}$ and is simply taken as exogenous in this paper.

The accuracy goal is a desire for one's opinion to be based on fact, possibly to strengthen one's belief and become more persuasive, to reduce "cognitive dissonance", or to not appear racist to oneself or others. A preference for accurate beliefs will clearly be favoured by evolution in many circumstances. Alchian (1950) and Friedman (1953) argue that economic agents who make decisions based on false beliefs will be eliminated from markets. More generally, humanity's desire to gain greater understanding our environment has been essential in the astounding technological progress of the past millenia.

In the model presented in Section 2, the concepts from the theory of motivated reasoning generates demand for beliefs. The supply side is provided

\footnotetext{
${ }^{6}$ Peck (1990) shows that outsider exclusion can be favoured by evolution, even when it incurs a large cost

7“(The) xenophobic principle has been documented in virtually every group of animals displaying higher forms of social organization... Human behaviour provides some of the best exemplification of the xenophobia principle." Wilson (2000)
} 
by the memory-management model of Benabou and Tirole (2002). The agent receives some information about the economic impact of immigrants, anything from a media article about a government report to an anecdote from a friend at the pub. They then process this signal in some way, which may involve either sub-conscious repression of undesirable information, or an attempt to actively convince themselves that the report is just "damn lies and statisics", or that the event described in the anecdote was just a one-off occurrence and in no way representative of the world at large. From the information that is retained, the agent forms a belief about the economic impact of immigrants and, based on this belief, forms an opinion on whether immigration numbers should be increased or decreased. The satisfaction they obtain from holding this opinion depends on a utility function that contains both a directional goal (whether the opinion is the one they want to hold), and accuracy goal (how close their opinion is to the belief they have formed).

Two results of the model are reasonably intuitive: firstly, a stronger desire not to live with foreigners results in more effort being put into discounting good news about immigrants, thus a higher chance of believing that immigrants are bad for the economy and holding the opinion that there should be fewer immigrants; secondly, the higher the probability of receiving a positive signal, the less effort is put into discounting it if it arrives.

A more complex result relates to the effect of accuracy goals on directional goals: do strong accuracy goals increase or decrease distortions in opinions due to the presence of a directional goal? On the one hand it seems intuitive that a greater desire for accuracy should reduce distortions, however people who would suffer large costs from coming to a conclusion they didn't like may put more effort into justifying the preferred conclusion. There are conflicting opinions on this question in the psychology and sociology literature. ${ }^{8}$ The model suggests that the effect of a stronger accuracy goal depends on the relative strength of the directional goal. If the directional goal is relatively weak, strengthening the

\footnotetext{
${ }^{8}$ Jackman and Muha (1984), for example, contains a review of the inconclusive debate on the effect of education on "intergroup negativism."
} 
accuracy goal results in less distortion of beliefs and a higher chance of wanting more immigrants; if the directional goal is sufficiently strong then the agent will want to reduce immigrant numbers regardless of their economic impact, and increasing the accuracy goal leads to more effort being put into manipulating beliefs. This last result is in line with Taber and Lodge.

A slight variation of the model shows how the demand for particular beliefs generated by motivated reasoning can be satisfied by selection of media sources. This gives an explanation of the demand for biased media, even for rational agents aware of the bias.

To test these results I use data from the European Social Survey 2002/2003. This dataset contains detailed questions relating to beliefs about the economic impact of immigrants, attitudes to race and ethnicity, as well as information about the socio-economic status of respondants which closely match variables in the model. Probit regressions find evidence to support the results derived from the model.

The economics literature on attitudes towards immigrants has largely been concerned with identifying the roles of "economic" and "non-economic" determinants: do people want to reduce the number of immigrants because it is in their economic self-interest, or because of prejudice or a perceived threat to their national identity. This is of importance to policy-makers who support immigration and those concerned about the discriminatory and often violent treatment of immigrants. If opposition to immigration is largely driven by economic concerns, these can be addressed through relatively simple policies, compensating those who lose out. If opposition is primarily caused by xenophobia, the issue is much more difficult. The empirical results of this paper show that it is extremely difficult to disentangle economic from non-economic factors.

Not surprisingly, racism is one of the strongest determinants of attitudes towards immigrants (Mayda, 2004). The model of Section 2 suggests that racism has not only a direct effect on attitudes, but also an effect on the formation of beliefs about immigrants and their economic impact. This will affect the other channels through which individual characteristics determine attitudes. For ex- 
ample, it is commonly argued that low-skilled workers should oppose immigration that will increase the ratio of low-skilled to high-skilled workers because of a negative impact on wages predicted by some factor endowment models (and a simple labour supply/labour demand argument). There is econometric evidence to suggest that indeed people do oppose immigration more strongly when immigrants are predominantly of their skill level, and this is treated as evidence that economic, as well as non-economic factors are important in formation of attitudes. However, given that most empirical evidence shows that immigration seems to have little negative impact on the work opportunities of natives, it is apparent that what is important is not economic factors, but perceived economic factors, that is beliefs.

Nikolaj Malchow-Moller and Skaksen (2006)move in this direction by regressing attitudes to immigrants not simply on individual characteristics (highskilled, low skilled etc), but also on these characteristics interacted with beliefs about the economic impact of migrants: poor people should oppose immigration only if they are poor and if they believe that the immigration is bad for the poor. Their paper finds that economic factors play a sizable and statistically significant role in peoples' opinions on whether immigrant numbers should be increased or decreased. However, if beliefs about the economic impact are determined endogenously with respect to opinions about immigrant numbers, as suggested here, these results could be spurious.

The only paper I am aware of that looks in any detail at the determinants of beliefs about the economic impact of immigrants is Thomas K. Bauer and Zimmermann (2000). The focus of their paper is cross-country differences in attitudes and how they relate to immigration policy. They use data from the International Social Science Project. Hainmueller and Hiscox (2007) note that the belief that immigrants are good for the economy is positively correlated with education.

An interesting empirical paper which presents results explained by this model, but not by traditional economic theory is Dustman and Preston (2000), which looks at whether attitudes to immigration in the UK are associated with racial 
attitudes, labour market or welfare concerns. They find that labour market concerns are significantly related with negative attitudes to immigration, but only among highly educated people. Among workers with little education, attitudes to immigration are only significantly associated with racial attitudes. This runs counter to what one would expect given that immigrants to the UK are more likely to be competing with low-skilled workers. However it is consistent with the notion that more educated people have stronger accuracy goals, and so have a stronger need to find reasons to justify their opinions.

\section{The Theory}

\subsection{Memory Management With Motivated Reasoning 9}

The agent receives a signal about some aspect of the economic impact of immigrants: the signal $\sigma=0$, received with probability $1-\rho$, is evidence that there should be fewer immigrants; $\sigma=1$, occuring with probability $\rho$, indicates that there should be more immigrants. If $\sigma=1$, the agent may try to forget or convince themselves it is false. They "choose" $\lambda$, the probability the information will be dismissed, at a pyschological cost $M(\lambda) \cdot{ }^{10}$ The information that is recalled is then $\hat{\sigma}=1$ if $\sigma=1$ and the agent fails to dismiss the information, and $\hat{\sigma}=1$ otherwise.

Based on this recall, the agent forms a belief $b=E[\sigma \mid \hat{\sigma}]$, according to Bayes law as they are aware of their tendency to manipulate information . If $\sigma=1$, then $b=1=b_{1}$, but if $\sigma=0$ then

$$
b=\frac{\rho \lambda}{1-\rho+\rho \lambda}=b_{0}
$$

Finally the agent takes an action $a=0(a=1)$ which is to support a policy of reducing (increasing) the number of immigrants. The utility from

\footnotetext{
${ }^{9}$ For a more detailed explanation and justification of the memory management side of this model, see Benabou and Tirole (2002).

${ }^{10}$ The case where $M(\lambda)=0$ is considered in the section 2.2 .
} 
from this action depends on three factors: the satisfaction of a directional goal, an accuracy goal, and the effort of manipulating information:

$$
U(a, b, \lambda)=\delta(1-a)-\alpha f(|b-a|)-M(\lambda)
$$

The parameter $\delta \geq 0$ represents the weight the agent places on the directional goal. This captures the preference for the agent to live in a society with fewer immigrants, and is increasing in strength of xenophobia, or preference for living in an ethnically homogenous country.

The parameter $\alpha \geq 0$ represents the strength of the accuracy goal (increasing in the desire to rationalize one's opinion). The function $f($.$) is the psychological$ cost of taking an action which is not justified by evidence, increasing in the distance of the action taken from what the agent believes to be objectively best, that is $f(0)=0$ and $f^{\prime}(x) \lessgtr 0, \forall x \lessgtr 0 . M($.)is assumed to be convex.

Lemma 1 After receiving the signal $\hat{\sigma}=0$ the agent will always choose $a=0$.

Proof: Suppose there is an equilibrium where the agent chooses $a=1$ after receiving the signal $\hat{\sigma}=0$. This implies that $U\left(1, b_{0}, \bar{\lambda}\right)>U\left(0, b_{0}, \bar{\lambda}\right)$ where $\bar{\lambda}$ is the equilibrium value of $\lambda$, i.e. $\delta-\alpha f\left(b_{0}\right)<-\alpha f\left(1-b_{0}\right)<0$. If the agent received the signal $\hat{\sigma}=1$ they would select $a=0$ if and only if $\delta-\alpha f(1)>$ 0 but $\delta-\alpha f(1)<\delta-\alpha f\left(b_{0}\right)<0$ because $b_{0}<1$. Therefore they must choose $a=1$ regardless of the signal. This gives them an expected utility of $-\lambda \alpha f\left(1-b_{0}\right)-M(\lambda)$ which is maximised by choosing $\lambda=0$. But if $\bar{\lambda}=0$ then $b_{0}=0$ and $U\left(0, b_{0}, \bar{\lambda}\right)=\delta>0=U\left(1, b_{0}, \bar{\lambda}\right)$.

Lemma 2 After receiving the signal $\hat{\sigma}=1$ the agent will choose $a=1$ if and only if $\delta<\alpha f(1)$.

Proof: $U(1,1, \bar{\lambda})=-M(\bar{\lambda})>\delta-\alpha f(1)-M(\bar{\lambda})=U\left(0, b_{0}, \bar{\lambda}\right)$ if and only if $\delta<\alpha f(1)$.

\section{Proposition 1}


a) If $\delta<\alpha f(1)$, the equilibrim value of $\lambda$ is decreasing in $\alpha$ and increasing in $\delta$.

b) If $\delta>\alpha f(1)$, the equilibrim value of $\lambda$ is increasing in $\alpha$ and unaffected by $\delta$.

c) The equilibrim value of $\lambda$ is decreasing in $\rho$.

Proof:

a) If $\delta<\alpha f(1)$, by Lemmas 1 and 2 , the agent solves $\max \lambda\left(\delta-\alpha f\left(b_{0}\right)\right)-$ $M(\lambda)$, which gives the first order condition $M^{\prime}(\lambda)^{\lambda}-\delta+\alpha f\left(b_{0}\right)=$ $0 .{ }^{11}$ Substituting for $b_{0}$ gives the condition for a perfect bayesian equilibrium ${ }^{12}$ :

$$
M^{\prime}(\lambda)-\delta+\alpha f\left(\frac{\rho \lambda}{1-\rho+\rho \lambda}\right)=0
$$

Differentiating with respect to $\alpha$ gives:

$$
\begin{aligned}
0 & =\frac{\partial \lambda}{\partial \alpha} M^{\prime \prime}(\lambda)+\alpha \frac{\partial b_{0}}{\partial \lambda} \frac{\partial \lambda}{\partial \alpha} f^{\prime}\left(b_{0}\right)+f\left(b_{0}\right) \\
\frac{\partial \lambda}{\partial \alpha} & =-\frac{f\left(b_{0}\right)}{M^{\prime \prime}(\lambda)+\alpha \frac{\partial b_{0}}{\partial \lambda} f^{\prime}\left(b_{0}\right)} \\
& <0
\end{aligned}
$$

because

$$
\frac{\partial b_{0}}{\partial \lambda}=\frac{\rho(1-\rho)}{(1-\rho+\rho \lambda)^{2}}>0
$$

\footnotetext{
${ }^{11}$ For simplicity I am ignoring the constraint that $0 \leq \lambda \leq 1$, and assuming that parameters are such that solutions are interior. Convexity of $M$ guarantees that if the first order condition specifies $\lambda<0$, then the constrained objective function is maximised at $\lambda=0$, and if $\lambda>1$ is specified then the optimal value is 1 . This is also true for all the following maximisation problems. Strictly speaking in Proposition 3, "increasing (decreasing)" should be "non-decreasing (non-increasing)," the difference only being relevant when the constraint on $\lambda$ is binding.

${ }^{12}$ Here a perfect Bayesian equilibrium is characterised by $\lambda$ being chosen optimally given the assessment of the reliability of $b_{0}$, and that assessment being determined by Bayes rule and the strategy used for selecting $\lambda$.
} 
Differentiating the equilibrium condition with respect to $\delta$ gives:

$$
\begin{aligned}
0 & =\frac{\partial \lambda}{\partial \delta} M^{\prime \prime}(\lambda)-1+\alpha \frac{\partial b_{0}}{\partial \lambda} \frac{\partial \lambda}{\partial \alpha} f^{\prime}\left(b_{0}\right) \\
\frac{\partial \lambda}{\partial \delta} & =\frac{1}{M^{\prime \prime}(\lambda)+\alpha \frac{\partial b_{0}}{\partial \lambda} f^{\prime}\left(b_{0}\right)} \\
& >0
\end{aligned}
$$

b) If $\delta>\alpha f(1)$, by Propositions 1 and 2, the agent solves $\max _{\lambda} \delta-$ $\alpha\left(\lambda f\left(b_{0}\right)+(1-\lambda) f(1)\right)-M(\lambda)$, which gives the first order condition $M^{\prime}(\lambda)-\alpha\left(f(1)-f\left(b_{0}\right)\right)=0$. The condition for a perfect bayesian equilibrium is now:

$$
M^{\prime}(\lambda)-\alpha\left(f(1)-f\left(\frac{\rho \lambda}{1-\rho+\rho \lambda}\right)\right)=0
$$

Differentiating with respect to $\alpha$ gives:

$$
\begin{aligned}
0 & =\frac{\partial \lambda}{\partial \alpha} M^{\prime \prime}(\lambda)+\alpha \frac{\partial b_{0}}{\partial \lambda} \frac{\partial \lambda}{\partial \alpha} f^{\prime}\left(b_{0}\right)-f(1)+f\left(b_{0}\right) \\
\frac{\partial \lambda}{\partial \alpha} & =-\frac{f(1)-f\left(b_{0}\right)}{M^{\prime \prime}(\lambda)+\alpha \frac{\partial b_{0}}{\partial \lambda} f^{\prime}\left(b_{0}\right)} \\
& >0
\end{aligned}
$$

Clearly the equilibrium condition is independent of $\delta$.

c) Differentiating either equilibrium condition with respect to $\rho$ gives:

$$
\begin{aligned}
0 & =\frac{\partial \lambda}{\partial \rho} M^{\prime \prime}(\lambda)+\alpha \frac{\frac{\partial \lambda}{\partial \rho}(1-\rho)+\lambda}{(1-\rho+\rho \lambda)^{2}} f^{\prime}\left(b_{0}\right) \\
\frac{\partial \lambda}{\partial \rho} & =-\frac{\alpha \lambda f^{\prime}\left(b_{0}\right)}{(1-\rho+\rho \lambda)^{2} M^{\prime \prime}(\lambda)+(1-\rho) f^{\prime}\left(b_{0}\right)} \\
& <0
\end{aligned}
$$

Figure 1 illustrates the first two parts of the proposition when $\rho=0.5, f(x)=$ 
$|x|$, and $M(\lambda)=0.5 \lambda^{2}$. The graph shows what happens to the equilibrium value of $\lambda$ when $\delta$ is held fixed at 0.5 and $\alpha$ varies between zero and one. Two regimes emerge: one where the agent can be swayed by the evidence $(\delta<\alpha f(1))$, and one where their mind is already made up $(\delta>\alpha f(1))$.

Increasing $\delta$ increases the value of increasing $\lambda$ only in so far as it increases the probability of choosing $a=0$. If $\delta>\alpha f(1)$, the agent always chooses $a=0$, so there is no point in increasing $\lambda$ further.

The differing effects of the accuracy goal can be understood as follows. There are two consequences of increasing $\lambda$ : the probability of receiving favourable information is increased, and $b$ is increased in the event that $\hat{\sigma}=0$. Manipulation means that the agent is more likely to receive the information they want, but it will be of less value because in equilibrium they "know" the degree of manipulation. In the first regime, strengthening the accuracy goal makes manipulation less desirable for two reasons: it directly reduces the benefit of receiving the preferred signal because of the increase in $\alpha$ (the payoff when $\hat{\sigma}=1$ is unchanged because in this case $a=b$ and there is no cost associated with the accuracy goal); it also indirectly reduces this benefit by increasing the uncertainty that $a=0$ is the correct action through the effect on $b$. Intuitively, the more the agent cares about making the correct decision, the less they will want to fool themselves given that they are aware of the self-deception.

When the signal is irrelevant to the decision of the agent, the costs of increasing the accuracy goal occur regardless of the signal that is recalled, but the increase will be greater when $\hat{\sigma}=1$ because $f(1)>f\left(b_{0}\right) \forall b_{0}$ thus there will be an incentive to increase the probability of receiving the favoured information despite the associated increase in $b_{0}$. Here there is a large benefit of receiving a signal that makes them feel good about the decision they are bound to make anyway.

The only effect of an increase in $\rho$ is to reduce the trustworthyness of the signal $\hat{\sigma}=0$. This reduces the value of manipulation in either regime. 


\subsection{A Variation: Selection of Media as Information Man- agement}

One major channel through which information about immigrants is acquired is the media. It could be argued that misperceptions about the economic impact of immigrants results simply from biased media. There are two major shortcomings with this argument. Firstly, where does the demand for biased media originate? ${ }^{13}$ If people have existing prejudices, why do they need to be told what they already "know." Secondly, people must be at least partially aware that the news they are receiving is biased if they are deliberately receiving it from a source they know to be biased, so why believe it?

These questions can be answered by a slight adjustment of the model presented in this paper. The parameter $\lambda$ can be thought of as the degree of bias of a particular news-source, giving the agent a choice of a continuum of sources with bias ranging from zero to one. Now $\lambda$ represents the probability that a story involving positive news about immigrants will be censored.

In most circumstances it would be unreasonable to suppose that selecting a more biased source would entail greater psychological costs (here the memory management equivalent, censoring, is done for you) so $M(\lambda)$ will be set to zero. ${ }^{14}$

\section{Proposition 2}

a) If $\delta<\alpha f(1)$, the equilibrim value of $\lambda$ is decreasing in $\alpha$ and $\rho$ and increasing in $\delta$.

b) If $\delta>\alpha f(1)$, in equilibrium $\lambda=1$.

The differences between Propositions 1 and 2 are entirely due to the absence of memory management costs. Without these costs it is always optimal for an individual with a sufficiently strong directional goal to isolate themselves completely from information that would contradict the position they want to

\footnotetext{
${ }^{13} \mathrm{~A}$ free and commercially driven media is assumed, abstracting from political manipulation

${ }^{14}$ There may, of course, be some social censure for consuming particularly extreme media
} 
(and certainly will) hold. They do this by choosing media that censors such information with probability one.

This model can resolve the two shortcomings mentioned above. There is demand for biased media when both directional and accuracy goals are present: people want to read what they already "know" in order to justify opinions they have an exogenous desire to hold. Also, even when agents are perfectly rational, they can still fool themselves to some extent, making it beneficial to consume media they know to be biased.

\section{Empirical Analysis}

\subsection{Estimation Strategy}

Without precise data about the prior beliefs of an individual, and knowledge of what new information they received, it is not possible to directly test the model $^{15}$. However, testing the general implications of the propositions derived from the model of Section 2 is relatively straight forward given reasonable proxies for $\alpha, \delta$ and $\rho$. In order to do this I estimate the following equation:

$$
\text { belief }_{i}=\gamma_{0} \delta_{i}+\gamma_{1} \delta_{i} \cdot \alpha_{i}+\gamma_{2} \alpha_{i}+\gamma_{3} P_{i}+\beta X_{i}+\epsilon_{i}
$$

where belie $f_{i}$ is a dummy variable which equals one if a given belief is held, $\delta_{i}$ and $\alpha_{i}$ are measures of the strength of an individual's directional and accuracy goals, $P_{i}$ is a vector of variables that could increase the probability of receiving positive signals, $X_{i}$ is a vector of other control variables, and $\epsilon_{i}$ is a random error.

The first hypothesis that will be tested is that the probability that one believes that immigrants are good for the economy (which in equilibrium is equal to $\rho(1-\lambda))$ is affected negatively by a preference against living in proximity to foreigners. This requires $\gamma_{0}<0$.

\footnotetext{
${ }^{15}$ This could be feasible in laboratory experiments à la Taber and Lodge
} 
Secondly, the effect of the accuracy goal should be negative for those with a strong directional goal, and positive for others. This would require the total effect of the $\gamma_{1}$ and $\gamma_{2}$ terms to be positive (negative ${ }^{16}$ ) for high (low) values of $\delta_{i}$. A necessary condition is $\gamma_{1}<0 .{ }^{17}$

The hypothesis that a higher probability of receiving good signals about immigration leads to more pro-immigrant beliefs would be supported by $\gamma_{3}>0$.

\subsection{Data}

To estimate the equation we need variables to proxy for the beliefs, directional goal and accuracy goal. The European Social Survey 2002/2003 provides the necessary data. The survey covers 22 countries: the EU-15, Norway, Switzerland, Poland, Czech Republic, Slovenia, Hungary and Israel.

\subsubsection{Belief Variables}

The first three dependent "belief" variables are generated from the following questions: "Would you say it is generally bad or good for [country]'s economy that people come to live here from other countries?", "Most people who come to live here work and pay taxes. They also use health and welfare services. On balance, do you think people who come here take out more than they put in or put in more than they take out?", and "would you say that people who come to live here generally take jobs away from workers in [country], or generally help to create new jobs? "The responses are on a scale from 0 to 10 , where 0 is the most negative view of the impact of immigrants and 10 is the most positive. For the final dependent variable the respondent is asked to what extent they agree with the following statement: "Average wages and salaries are generally brought down by people coming to live and work here." The answers range from 1 (agree strongly) to 5 (disagree strongly). The questions are converted

\footnotetext{
${ }^{16}$ or zero for the media selection version of the model

${ }^{17}$ Strictly speaking this can only be derived from the model under certain assumptions about the support of $\alpha$ and $\delta$ in the data e.g. if $\delta$ is binary then the support of $\alpha$ would have to be $[0,1]$. However I think that expecting a negative interaction term captures well the flavour of the proposition.
} 
into a dummy variables (econ, fiscal, jobs and wage), taking the value 1 if the respondent thinks that immigrants are beneficial, and 0 if the respondent thinks that immigrants are harmful or have no impact. ${ }^{18}$ Descriptive statistics of these variables in the sample used for the main analysis are contained in Table XXX.

\subsubsection{Directional goal}

Two alternative variables are used for the directional goal. For the first, ideallive, I use the following question: "Suppose you were choosing where to live. Which of the three types of area on this card would you ideally wish to live in?: An area where almost nobody was of a different race or ethnic group from most [country] people (1), Some people were of a different race or ethnic group from most [country] people (2), Many people were of a different race or ethnic group (3), It would make no difference (4)." The variable ideallive is one if the response to this question is (1), and zero for other responses. ${ }^{19}$

Strictly speaking, this variable only makes sense as a directional goal in this context if the respondent is of the majority ethnic group. For this reason, in the results that are presented here, the sample is restricted to such individuals. The results are robust to lifting this restriction.

The second uses responses to the statement "it is better for a country if almost everyone shares the same customs and traditions." The variable sameculture takes a value from 1 if the respondent strongly disagrees with the statement, to 5 if they strongly agree.

These variables are indications of a desire to live in an ethnically or culturally homogenous society, which provides a reason to oppose immigration that is not related to its macroeconomic impact.

\footnotetext{
${ }^{18} \mathrm{I}$ assume that most respondents would take the view that an increase in average wages is beneficial.

${ }^{19}$ All the main results are robust to replacing ideallive with dummy variables for each reponse, or a single variable taking the values 1 to 4 .
} 


\subsubsection{Accuracy goal}

Again, I try two alternatives to proxy for the accuracy goal. The first is years of education $(e d u c)$. An essential part of education is training people to argue logically, present and defend ideas and arguments. More educated people should be more likely to feel that justifying decisions with evidence is desirable and feel a stronger need to do so.

The second proxy (nwsnp) is time spent reading about politics and current affairs in newspapers. Reading about these issues in a newspaper enables people to find facts to develop an informed opinion. Presumably people who spend more time doing this are more likely to think it important that their opinions are based on evidence. The variable takes the following values: 0 (no time at all), 1 (less than $1 / 2$ hour), 2 ( $1 / 2$ hour to 1 hour), 3 (more than 1 hour, up to $11 / 2$ hours), 4 (more than $11 / 2$ hour, up to 2 hours), 5 (more than 2 hour, up to $21 / 2$ hours), 6 (more than $21 / 2$ hour, up to 3 hours), 7 (more than 3 hours).

\subsubsection{Controls}

The dummy variable male is set to one if the respondent is male, birth year is the year of birth and urban is a dummy which equals one if the respondent lives in a town or city. The variable immigrant parents is the number of the respondents parents who are immigrants, and immigrant friends is $1 / 2 / 3$ if the respondent has no/a few/several friends who have are immigrants. Political orientation is captured by left-right, which is on a scale from 0 to 10 , with 10 being the most right-wing. The dummy variables high skill, retired, unemployed and paid employment are set to one if the respondent falls into that category. Being high skilled is defined according to ISCO occupation codes and includes legislators, managers, professionals and technicians. Unemployment includes only those seeking employment. Income is measured on a categorical scale from 1 to $12 .^{20}$ Summary statistics of these variables can be found in Table $2 . X_{i}$

\footnotetext{
${ }^{20} 1$ = less than 150 Euro monthly; $2=150-300$ Euro; $3=300-500 ; 4=500-1000 ; 5=1000$ $1500 ; 6=1500-2000 ; 7=2000-2500 ; 8=2500-3000 ; 9=3000-5000 ; 10=5000-7500 ; 11=$
} 
also contains a full set of country dummies.

\subsection{Results}

The equation is estimated using a probit model. ${ }^{21}$ Observations are weighted to take into account country population size and non-random sampling within countries as advised in the ESS guidelines. All four possible combinations of accuracy and direction goals are estimated. When nwsnp is used, years of education is also controlled for to account for aspects of education not related to accuracy concerns. Results are presented in Table 3. The marginal effect of the interaction term is calculated using the "inteff" Stata command. ${ }^{22}$

The effect of a preference against living with people of a different ethnicity is strongly associated with a reduction in the probability of holding beliefs about a positive economic impact of immigrants: the coefficients are all negative, and mostly significant. This effect is large, reducing the probability of holding positive beliefs by between 3 and 18 percentage points. A preference for cultural homogeneity has a similar effect.

The coefficient on the interaction term is also always negative, and significant for half the regressions. To give an idea of the magnitude of this effect we can consider the change implied by increasing the number of years of education from 12 to 16 (roughly the difference between completion of high school and completion of a university degree) for different values of ideallive. For ideallive = 0 , the probability that the respondent believes that immigrants are good for the economy increases by $8.4 \%$, whereas if the respondent has a strong preference against living near people of a different ethnicity the increase is only $5.9 \%$. Someone who spends more than 3 hours per day reading news about politics and current affairs is $18.9 \%$ more likely to believe that immigration creates employment than someone who spends no time if they have no preference for cultural homogeneity ( sameculture $=1$ ), however that figure is only $2.6 \%$ if they

7500-10000; 12 = more than 10000

${ }^{21}$ The results are qualitatively unchanged when OLS is used

${ }^{22}$ For details of the program, and why it is necessary, see Ai et al. (2004) 
have a strong preference ( sameculture $=5) .{ }^{23}$

The total effect of an increase in years of education and nwsnp is always positive, albeit reduced by a strong directional goal. If the only consequence of education or reading a newspaper was to strengthen accuracy goals, then this would run counter to the prediction of the model that the effect should differ in sign depending on the strength of the directional goal. However it is likely that these variables will be to some degree associated with greater economic literacy which could increase the likelihood that individuals have more positive beliefs about the economic impact of immigration. It may also be associated with greater exposure to positive signals about the economic impact of immigrants, for example by meeting more highly educated immigrants in the case of education.

One interesting finding is that older people are significantly more likely to believe that immigrants are good for the economy in all the ways considered here. $^{24}$ This result is in contrast to the literature which finds that older people tend to be more strongly against immigration, and highlights the importance of non-economic factors in the formation of opinions about whether immigrant numbers should be increased or decreased. That people who formed their economic beliefs in the fifties and sixties believe that immigrants are good for the economy can be explained by the fact that this was a time when immigration was being actively encouraged by most European governments so there was a high probability of hearing pro-immigration evidence from official sources.

The coefficients on high skill and income are also consistently positive, and significant for all dependent variables apart from fiscal. High-skill and wealthy individuals are more likely to know high-skill and wealthy immigrants, that is those who are more likely to have high wages or set up businesses creating employment.

The probability of all four pro-immigrant beliefs is increasing in the number

\footnotetext{
${ }^{23}$ These are the point estimates calculated using Clarify, a program written by Gary King et al.King et al. (2000) The figures presented are based on the regressions with the full set of controls, and all variables other than educ and ideallive set at their mean.

${ }^{24}$ This was also found by Bauer et al. (2000) using a variable similar to econ.
} 
of immigrant parents and friends. One possibility is that having immigrant parents and friends increases the likelihood of receiving positive signals. Another is that having immigrant friends can be viewed as a proxy for a preference for having an ethnically diverse society. This would provide a directional working in the opposite direction to ideallive and nwsnp, increasing the probability of an individual ignoring bad signals about the economic impact of immigrants. Similarly, to the extent that supporters of right wing parties have a more exclusive concept of national identity, the fact that coefficient on the political orientation variable left-right is negative and highly significant for all four beliefs can be explained as representing another directional goal in the same direction as ideallive. ${ }^{25}$

The only variable that is significant with different signs for different beliefs is male: men are more likely to believe that immigrants increase employment and decrease wages. This is consistent with men thinking in terms of a simple supply and demand set-up. Immigration (an increase in labour supply), would then have those effects. Men are also more likely to think that immigration is good for the economy in general, which is a possible contradiction my assumption that respondents to the survey would consider a reduction in wages as a negative impact.

People living in a rural area are less likely to believe that immigrants have a negative fiscal impact. This could be because immigrants in rural areas are more likely to work in cash-in-hand jobs and thus pay less tax than immigrants working in urban areas.

\subsection{Robustness}

The first claim for robustness is the similarity in patterns of effects of accuracy goals, directional goals, and their interaction across a range of economic beliefs and using combinations of two different proxies for preferences. The importance

\footnotetext{
${ }^{25}$ Using left-right in place of ideallive in the interaction term finds significant and negative interaction effects for dependent variables fiscal and wage. The interaction coefficients on econ and $j o b s$ are also negative. Using $i m f r$ instead gives positive coefficients on the interaction terms as predicted, significant at the $5 \%$ level in the fiscal regression.
} 
of the range of beliefs is discussed in section 4 .

Several alternative definitions of the dependent variable have been tested: retaining the original values from the questionnaire $(0-10$, for econ, fiscal, and jobs; 1-5 for wage), and using a dummy variable as in the reported results but either eliminating the middle value or giving it a value of 1 instead of 0 . The major differences are in the significance of the interaction terms; other results are for the most part unchanged. ${ }^{26}$ When the middle value is excluded, all interaction terms are negative, with seven being significant at the 1 or $5 \%$ level. However, when the middle value is set to 1 , five of the 16 possible interaction terms become positive (but none significant), with only one being both negative and significant. Using all values, 14 out of 16 interaction terms are negative, but only one significantly so.

Two things make the reported dependent variables most appropriate. Firstly, a dummy variable is preferable to the values reported in the questionnaire, because it should reduce measurement error: only the extremes of the scale (0 and 10) were clearly defined, so it is not clear that one person who gave a response of 8 is really more firm in their belief than a different person who responded with a 7 . On the other hand, it does seem reasonable to assume that a response below the middle value indicates a belief in the opposite direction to a response above the middle value, and that the middle value indicates no firm belief. Secondly, the middle value has been included with negative beliefs because it fits better the idea behind the model, and also the evidence from psychology experiments: people forget or dismiss information they do not want; they are not at liberty to invent beliefs that suit them.

\section{Discussion}

Negative beliefs about the economic impact of immigrants are strongly related to a desire to live in an ethnically homogenous area. It is difficult to explain this

\footnotetext{
${ }^{26}$ A notable exception is the effect of male on fiscal, which loses significance when the middle value is excluded, and becomes significantly negative when the middle value is set to 1 .
} 
without recourse to something like motivated reasoning. The beliefs are related to the macroeconomy whereas the explanatory variable relates to the locality the respondent would like to live in. For the belief that immigrants have a negative fiscal impact one could create a chain of reasoning that this belief coincides with a belief that immigrants tend to be unemployed, thus poorer, and so the areas they live in are less desirable, and if immigrants are also believed to be from a different ethnic group then this would explain the correlation. On the other hand, this sort of argument falls down for beliefs about immigrants taking jobs from natives.

Negative beliefs about the economic impact of immigrants are also strongly to the belief that cultural homogeneity is better for a country. Of course if cultural homogeneity improves communication and cooperation then immigration from different cultures would have a direct negative impact on economic growth (if this was not counteracted by the flow of new ideas, or complementarities between people of different cultures), but it is difficult to see how economic reasoning could convincingly relate a desire for cultural homogeneity to the labour market beliefs considered here.

What alternative explanations are there for the interaction effect between education and xenophobia? One possibility is that those who have grown up in an ethnically homogenous area have also acquired a desire to live in such an area, perhaps from their parents who chose to live there in the first place. For such people, local schooling would have resulted in less contact with immigrants from ethnic minorities, and fewer opportunities to develop favourable views about them. However it is unclear why unfavourable views about their economic impact should develop in the absence of a motivational reasoning type argument.

The range of beliefs considered here is particularly important, as it suggests that the link between xenophobia and beliefs is not based on simple stereotypes. If the reason that people didn't want to live around members of a different ethnicity was because of negative stereotypes about characteristics of that ethnicity, such as laziness or criminality, then one would expect them to have negative beliefs about the impact immigration of people of that ethnicity on the economy 
in general and on government finances. However these negative stereotypes are not consistent with the beliefs that immigrants take jobs from natives and work for low wages, which would suggest immigrants are not lazy but at least as hard-working as natives. All beliefs studied here, whether they imply positive or negative stereotypes of immigrants, are influenced in the same way by proxies for accuracy goals, directional goals and their interactions.

Alternative explanations and objections about choice of proxies may be raised against any given regression presented here, but the fact that the results are so consistent across a variety of proxies and beliefs, speaks loudly in favour of this model of motivated reasoning.

These results demonstrate all kinds of difficulties in analysing the determinants of attitudes towards immigration. Typically in the existing literature a variable indicating whether an individual wants more or fewer immigrants is regressed on variables which may include a measure of individual skill-level, education, beliefs about social or economic impact of immigrants, sometimes a measure of racism, and sometimes country level information which in theory should indicate the skill-level of immigrants.

The first problem with using beliefs is one of reverse causality: rather than wanting less immigration because they believe immigrants have a harmful impact, people may believe immigrants have a harmful impact because they want fewer immigrants. Secondly, the desire to reduce immigration and beliefs that immigrants are harmful are both partly determined by xenophobia, resulting in missing variable bias if this is not carefully controlled for.

Education and a high skill-level, both often used in looking for the role of economic self interest in attitudes towards immigrants, are strongly correlated with positive beliefs about the economic impact of immigrants, and negatively correlated with xenophobia.

Finally, it is dangerous to interpret GDP as simply a proxy for skill-levels in a country as has been done in some previous papers, because it is also significantly negatively correlated with average levels of xenophobia. Figure 3 shows the average level of the variable sameculture in a country, plotted against 2002 per- 
capita GDP.

\section{Conclusion}

Different people have different beliefs about the facts of immigration. This can partially be explained by people receiving different signals, but even controlling for important socio-economic factors, beliefs vary systematically according to preferences that are not directly related to the economics of immigration. This systematic variation is consistent with the predictions of a model of belief formation based on the concept of motivated reasoning. An additional contribution of this paper is to provide a theoretical model which explains the demand for biased media in rational agents who are aware of the bias. 


\section{References}

Ai, Chunrong, Edward C. Norton, and Hua Wang, "Computing interaction effects and standard errors in logit and probit models," The Stata Journal, 2004, 4 (2), 154-167.

Alchian, Armen A., "Uncertainty, Evolution, and Economic Theory," The Journal of Political Economy, June 1950, 58 (3), 211-221.

Barro, Robert and Xavier Sala-i-Martin, "Regional Growth and Migration: A Japan-United States Comparison," Journal of the International and Japanese Economies, 1992, 6, 312-346.

Bauer, Magnus Lofstrom Thomas K. and Klaus F. Zimmermann, "Immigration Policy, Assimilation of Immigrants and Native's Sentiments towards Immigrants: Evidence from 12 OECD-Countries," IZA Discussion Paper No. 187, August 2000.

Benabou, Roland and Jean Tirole, "Self Confidence and Personal Motivation," The Quarterly Journal of Economics, 2002, 117 (3), 871-915.

Blanchflower, David G., Jumana Saleheen, and Chris Shadforth, "The impact of the Recent Migration from Eastern Europe on the UK Economy," IZA Discussion Paper No. 2615, February 2007.

Borjas, George J., "The Labour Demand Curve is Downward Sloping: Reexamining the Impact of Immigration on the Labour Market," The Quarterly Journal of Economics, 2003, 118 (4), 1335-1374.

Caplan, Bryan, "Systematically Biased Beliefs About Economics: Robust evidenceof judgemental anomalies from the Survey of Americans and Economists on the Economy," The Economic Journal, 2002, 112, 433-458.

Dustman, Christian and Ian Preston, "Racial and Economic Factors in Attitudes to Immigration," IZA Discussion Paper No. 190, August 2000. 
Esterhazy, Peter, "Celestial Harmonies," Harper Perennial, 2005.

Freidberg, Rachel M. and Janet Hunt, "The Impact of Immigrants on Host Country Wages, Employment and Growth," Journal of Economic Perspectives, 1995, 9 (2), 23-44.

Friedman, Milton, "Essays in Positive Economics," University of Chicago Press, 1953.

Gott, Ceri and Karl Johnston, "The Migrant Population in the UK: Fiscal Effects," Home Office Research, Development and Statistics Directorate Occasional Working Paper No. 77, 2002.

Hainmueller, Jens and Michael J. Hiscox, "Educated Preferences: Explaining Attitudes Toward Immigration in Europe," International Organization, 2007, 61 .

Hunt, Jennifer and Marjolaine Gauthier-Loiselle, "How Much Does Immigration Boost Innovation," IZA Discussion Paper No. 3921, 2009.

Jowell, Roger and the Central Co-ordinating Team, "European Social Survey 2002/2003," Technical Report, London: Centre for Comparative Social Surveys, City University 2003.

King, Gary, Michael Tomz, and Jason Wittenburg, "Making the Most of Statistical Analyses: Improving Interpretation and Presentation," American Journal of Political Science, April 2000, 44 (2), 347-361.

Kunda, Ziva, "The Case for Motivated Reasoning," Psychological Bulletin, 1990, $108(3), 480-498$.

Munch, Sannes Schroll Nikolaj Malchow-Moller Jakob Roland and Jan Rose Skaksen, "Attitudes Towards Immigration: Does Economic SelfInterest Matter?," IZA Discussion Paper No. 2283, September 2006.

Nana, Ganesh and Julian Williams, "Fiscal Impact of Migrants to New Zealand," Technical Report, New Zealand Department of Labour 1999. 
Peck, Joel R., "The Evolution of Outsider Exclusion," Journal of Theoretical Biology, 1990, 142, 565-571.

Taber, Charles S. and Milton Lodge, "Motivated Skepticism in the Evaluation of Political Beliefs," American Journal of Political Science, 2006, 50 (3), $755-769$.

Wilson, Edward O., "Sociobiology: The New Synthesis," Harvard University Press, 2000. 
Figure 1: Equilibrium $\lambda$

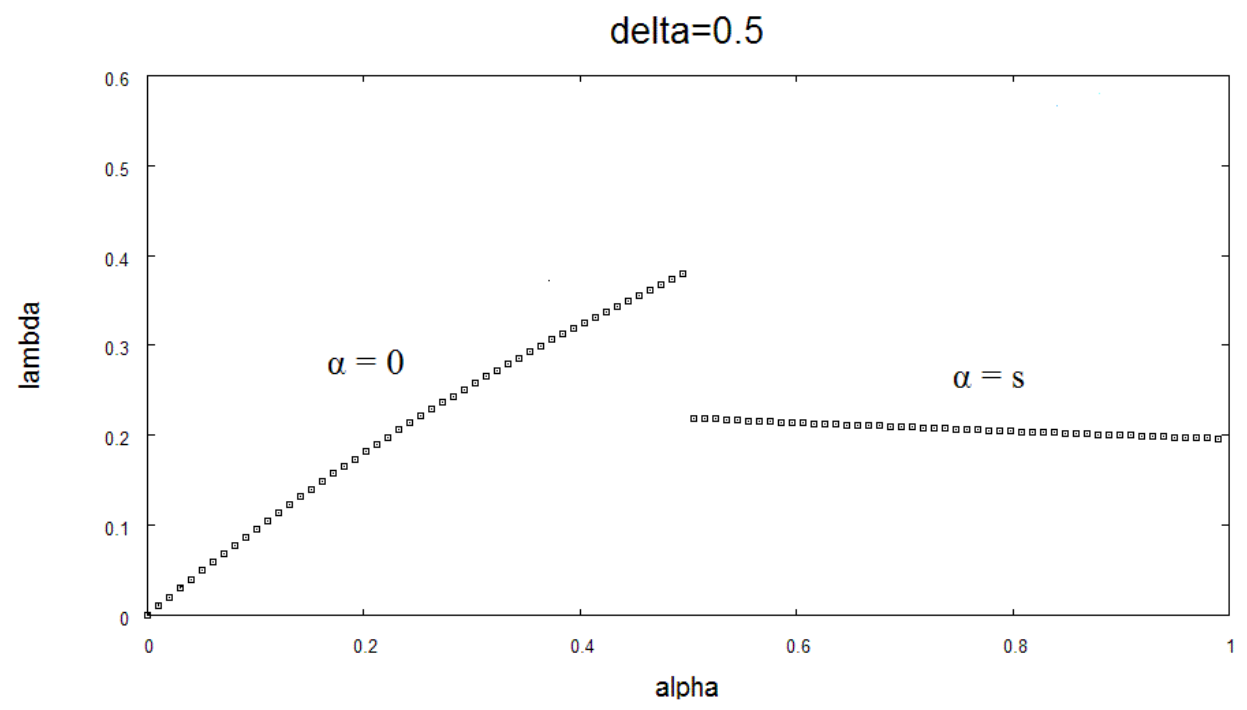

Figure 2: Country average "sameculture" vs per-capita GDP

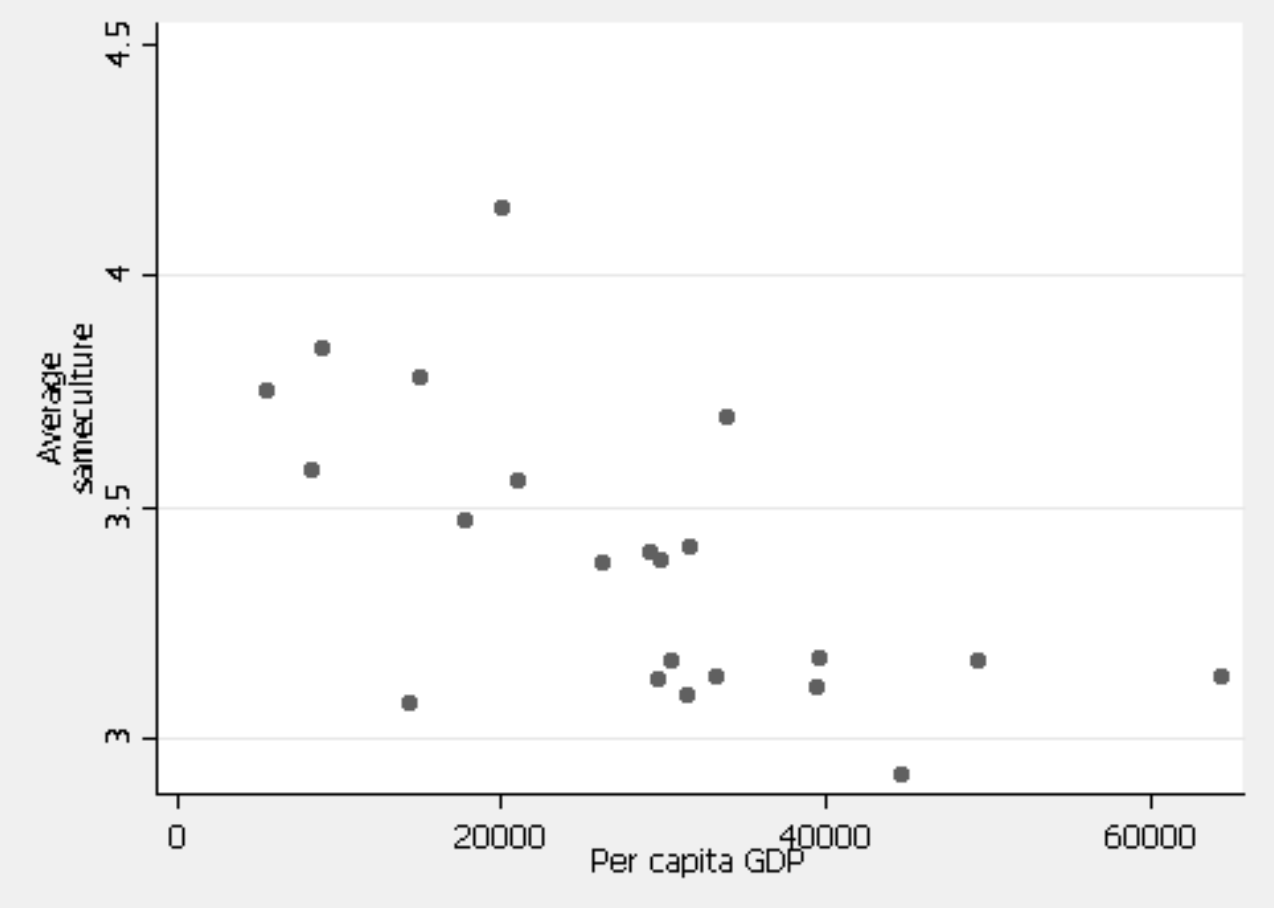


Table 1: Belief variables, summary statistics

\begin{tabular}{lcc}
\hline Variable & Obs & Mean \\
\hline econ & 39769 & 0.38 \\
fiscal & 39551 & 0.21 \\
jobs & 40455 & 0.26 \\
wage & 39828 & 0.37
\end{tabular}

Table 2: Independent variables, summary statistics

\begin{tabular}{lccc}
\hline Variable & Obs & Mean & Std. Dev. \\
\hline educ & 41717 & 11.85 & 4.03 \\
nwsnp & 31645 & 1.25 & 0.94 \\
ideallive & 41179 & 0.33 & 0.47 \\
sameculture & 41638 & 3.37 & 1.11 \\
birthyear & 42101 & 1955 & 18.28 \\
& & & \\
male & 42304 & 0.47 & 0.5 \\
urban & 42159 & 0.62 & 0.48 \\
immigrant parents & 42071 & 0.27 & 0.64 \\
immigrant friends & 42109 & 0.63 & 0.74 \\
left-right & 37144 & 5.07 & 2.2 \\
& & & \\
highskill & 36722 & 0.49 & 0.5 \\
retired & 41758 & 0.12 & 0.33 \\
unemployed & 41758 & 0.03 & 0.17 \\
in paid employment & 41758 & 0.49 & 0.5
\end{tabular}


Table 3: Belief variables by country

\begin{tabular}{lcccc}
\hline & Econ & Fiscal & Wage & Jobs \\
\hline Austria & 0.47 & 0.24 & 0.35 & 0.24 \\
Belgium & 0.3 & 0.18 & 0.5 & 0.2 \\
Switzerland & 0.55 & 0.18 & 0.32 & 0.25 \\
Czech Republic & 0.26 & 0.14 & 0.43 & 0.15 \\
Germany & 0.4 & 0.13 & 0.31 & 0.15 \\
& & & & \\
Denmark & 0.35 & 0.2 & 0.62 & 0.43 \\
Spain & 0.44 & 0.26 & 0.42 & 0.32 \\
Finland & 0.45 & 0.23 & 0.34 & 0.35 \\
France & 0.37 & 0.2 & 0.29 & 0.32 \\
Great Britain & 0.27 & 0.19 & 0.34 & 0.22 \\
& & & & \\
Greece & 0.22 & 0.16 & 0.09 & 0.12 \\
Hungary & 0.2 & 0.09 & 0.18 & 0.11 \\
Ireland & 0.38 & 0.16 & 0.41 & 0.22 \\
Israel & 0.39 & 0.27 & 0.19 & 0.24 \\
Italy & 0.42 & 0.33 & 0.42 & 0.32 \\
Luxembourg & 0.66 & 0.27 & 0.45 & 0.37 \\
Netherlands & 0.34 & 0.24 & 0.55 & 0.32 \\
Norway & 0.45 & 0.27 & 0.59 & 0.45 \\
Poland & 0.27 & 0.17 & 0.32 & 0.18 \\
Portugal & 0.4 & 0.49 & 0.32 & 0.17 \\
Slovenia & 0.24 & 0.16 & 0.41 & 0.17
\end{tabular}


Table 4: Accuracy and directional goal variables by country

\begin{tabular}{|c|c|c|c|c|}
\hline & educ & nwsnp & ideallive & sameculture \\
\hline Austria & 12.32 & 1.3 & 0.34 & 3.09 \\
\hline Belgium & 12.2 & 1.11 & 0.41 & 3.39 \\
\hline Switzerland & 10.84 & 1.3 & 0.17 & 2.92 \\
\hline Czech Republic & 12.42 & 1.17 & 0.38 & 3.84 \\
\hline Germany & 12.83 & 1.23 & 0.24 & 3.13 \\
\hline Denmark & 13.19 & 1.35 & 0.37 & 3.17 \\
\hline Spain & 10.21 & 1.27 & 0.33 & 3.56 \\
\hline Finland & 11.96 & 1.24 & 0.31 & 3.41 \\
\hline France & 11.94 & 1.23 & 0.23 & 3.4 \\
\hline Great Britain & 12.72 & 1.14 & 0.26 & 3.17 \\
\hline Greece & 9.74 & 1.27 & 0.44 & 4.15 \\
\hline Hungary & 11.65 & 1.11 & 0.69 & 3.58 \\
\hline Ireland & 12.99 & 1.55 & 0.34 & 3.11 \\
\hline Israel & 12.82 & 1.43 & 0.41 & 3.47 \\
\hline Italy & 10.73 & 1.14 & 0.28 & 3.38 \\
\hline Luxembourg & 12.06 & 1.32 & 0.25 & 3.14 \\
\hline Netherlands & 12.85 & 1.32 & 0.32 & 3.13 \\
\hline Norway & 13.25 & 1.39 & 0.23 & 3.17 \\
\hline Poland & 11.4 & 0.97 & 0.33 & 3.75 \\
\hline Portugal & 7.44 & 1.34 & 0.37 & 3.78 \\
\hline Sweden & 12.01 & 1.17 & 0.2 & 3.07 \\
\hline Slovenia & 11.38 & 0.88 & 0.35 & 3.69 \\
\hline
\end{tabular}




\section{Probit regression: Immigrants are good for the economy}

\begin{tabular}{|c|c|c|c|c|}
\hline COEFFICIENT & (1) & $(2)$ & (3) & $(4)$ \\
\hline educ & $\begin{array}{c}0.0190 * * * \\
(0.00265)\end{array}$ & $\begin{array}{c}0.0226^{* * *} \\
(0.00479)\end{array}$ & $\begin{array}{c}0.0156^{* * *} \\
(0.00282)\end{array}$ & $\begin{array}{c}0.0145^{* * *} \\
(0.00281)\end{array}$ \\
\hline nwsnp & & & $\begin{array}{c}0.0298 * * * \\
(0.00592)\end{array}$ & $\begin{array}{c}0.0533 * * \\
(0.0211)\end{array}$ \\
\hline ideallive & $\begin{array}{c}-0.114^{* * *} \\
(0.0384)\end{array}$ & & $\begin{array}{c}-0.177^{* * * *} \\
(0.0235)\end{array}$ & \\
\hline sameculture & & $\begin{array}{c}-0.0548^{* * * *} \\
(0.0186)\end{array}$ & & $\begin{array}{c}-0.0708^{* * *} \\
(0.0132)\end{array}$ \\
\hline educ*ideallive & $\begin{array}{c}-0.00886^{* * * *} \\
(0.00397)\end{array}$ & & & \\
\hline educ*sameculture & & $\begin{array}{r}-0.00197 \\
(0.00132)\end{array}$ & & \\
\hline nwsnp*ideallive & & & $\begin{array}{r}-0.0104 \\
(0.0147)\end{array}$ & \\
\hline nwsnp ${ }^{*}$ sameculture & & & & $\begin{array}{c}-0.00802 \\
(0.00709)\end{array}$ \\
\hline bthyr & $\begin{array}{c}-0.00248 * * * \\
(0.000287)\end{array}$ & $\begin{array}{c}-0.00261 * * * \\
(0.000325)\end{array}$ & $\begin{array}{c}-0.00195 * * * \\
(0.000356)\end{array}$ & $\begin{array}{c}-0.00200^{* * *} \\
(0.000398)\end{array}$ \\
\hline male & $\begin{array}{c}0.0833^{* * * *} \\
(0.00954)\end{array}$ & $\begin{array}{l}0.0881^{* * * *} \\
(0.0105)\end{array}$ & $\begin{array}{c}0.0928^{* * * *} \\
(0.0103)\end{array}$ & $\begin{array}{c}0.0951^{* * *} \\
(0.0118)\end{array}$ \\
\hline urban & $\begin{array}{l}0.0184 \\
(0.0147)\end{array}$ & $\begin{array}{l}0.0204 \\
(0.0159)\end{array}$ & $\begin{array}{l}0.0204 \\
(0.0153)\end{array}$ & $\begin{array}{l}0.0209 \\
(0.0167)\end{array}$ \\
\hline parim & $\begin{array}{c}0.0253^{* *} \\
(0.0104)\end{array}$ & $\begin{array}{l}0.0280^{* * * *} \\
(0.0102)\end{array}$ & $\begin{array}{l}0.0233 \\
(0.0173)\end{array}$ & $\begin{array}{c}0.0288^{*} \\
(0.0158)\end{array}$ \\
\hline imfriend & $\begin{array}{c}0.0777^{* * * *} \\
(0.00663)\end{array}$ & $\begin{array}{c}0.0770^{* * * *} \\
(0.00614)\end{array}$ & $\begin{array}{c}0.0773^{* * *} \\
(0.00998)\end{array}$ & $\begin{array}{c}0.0767^{* * * *} \\
(0.00881)\end{array}$ \\
\hline $\operatorname{lr}$ & $\begin{array}{c}-0.0160^{* * *} \\
(0.00366)\end{array}$ & $\begin{array}{c}-0.0139 * * * \\
(0.00360)\end{array}$ & $\begin{array}{c}-0.0170^{* * *} \\
(0.00431)\end{array}$ & $\begin{array}{c}-0.0145^{* * *} \\
(0.00420)\end{array}$ \\
\hline highskill & $\begin{array}{c}0.0602^{* * * *} \\
(0.00918)\end{array}$ & $\begin{array}{l}0.0618^{* * * *} \\
(0.0112)\end{array}$ & $\begin{array}{c}0.0624^{* * *} \\
(0.0127)\end{array}$ & $\begin{array}{c}0.0614^{* * * *} \\
(0.0139)\end{array}$ \\
\hline retired & $\begin{array}{c}-0.0212^{*} \\
(0.0109)\end{array}$ & $\begin{array}{c}-0.0206^{* *} \\
(0.00967)\end{array}$ & $\begin{array}{c}-0.0224^{* *} \\
(0.0110)\end{array}$ & $\begin{array}{c}-0.0222^{*} \\
(0.0113)\end{array}$ \\
\hline unemp & $\begin{array}{c}-0.0496 * * * \\
(0.0154)\end{array}$ & $\begin{array}{c}-0.0519 * * * \\
(0.0164)\end{array}$ & $\begin{array}{c}-0.0640^{* *} \\
(0.0262)\end{array}$ & $\begin{array}{c}-0.0705^{* * *} \\
(0.0278)\end{array}$ \\
\hline paidemp & $\begin{array}{r}-0.0138 \\
(0.0139)\end{array}$ & $\begin{array}{r}-0.0185 \\
(0.0158)\end{array}$ & $\begin{array}{r}-0.0130 \\
(0.0167)\end{array}$ & $\begin{array}{r}-0.0191 \\
(0.0182)\end{array}$ \\
\hline $\begin{array}{l}\text { Observations } \\
\text { Pseudo } R^{2}\end{array}$ & $\begin{array}{c}27562 \\
0.0984\end{array}$ & $\begin{array}{c}27892 \\
0.0999\end{array}$ & $\begin{array}{l}21830 \\
0.103\end{array}$ & $\begin{array}{l}22087 \\
0.105\end{array}$ \\
\hline
\end{tabular}

The sample includes only citizens of the majority ethnic group. Marginal effects holding all other variables at their mean value are shown with robust standard errors adjusted for clustering by country. The marginal effect, standard errors and statistical significance of the interaction terms are calculated using the stata program inteff.ado written by Edward Norton et al. *significant at $10 \% * *$ significant at $5 \% * * *$ significant at $1 \%$. Country dummies are included in all estimations (coefficients not shown). Observations are weighted according to ESS guidelines. 


\section{Probit regression: Immigrants have a positive fiscal impact}

\begin{tabular}{|c|c|c|c|c|}
\hline COEFFICIENT & (1) & $(2)$ & $(3)$ & $(4)$ \\
\hline educ & $\begin{array}{c}0.00628^{* * *} \\
(0.00167)\end{array}$ & $\begin{array}{c}0.0119 * * * \\
(0.00356)\end{array}$ & $\begin{array}{c}0.00648^{* * *} \\
(0.00193)\end{array}$ & $\begin{array}{c}0.00579^{* * *} \\
(0.00173)\end{array}$ \\
\hline nwsnp & & & $\begin{array}{l}0.00302 \\
(0.00874)\end{array}$ & $\begin{array}{c}0.00515 \\
(0.0110)\end{array}$ \\
\hline ideallive & $\begin{array}{c}-0.0338 \\
(0.0257)\end{array}$ & & $\begin{array}{c}-0.0712^{* * *} \\
(0.0103)\end{array}$ & \\
\hline sameculture & & $\begin{array}{l}-0.0121 \\
(0.0120)\end{array}$ & & $\begin{array}{c}-0.0412^{* * *} \\
(0.00377)\end{array}$ \\
\hline educ*ideallive & $\begin{array}{c}-0.00511^{* * *} \\
(0.001794)\end{array}$ & & & \\
\hline educ* sameculture & & $\begin{array}{c}-0.00281^{* * *} \\
(0.000990)\end{array}$ & & \\
\hline nwsnp $*_{\text {ideallive }}$ & & & $\begin{array}{l}-0.00818 \\
(0.005258)\end{array}$ & \\
\hline newsnp ${ }^{*}$ sameculture & & & & $\begin{array}{l}-0.00134 \\
(0.002431)\end{array}$ \\
\hline bthyr & $\begin{array}{c}-0.000668 * * \\
(0.000318)\end{array}$ & $\begin{array}{c}-0.000766^{* *} \\
(0.000301)\end{array}$ & $\begin{array}{c}-0.000882^{* * *} \\
(0.000283)\end{array}$ & $\begin{array}{c}-0.000987^{* * *} * \\
(0.000301)\end{array}$ \\
\hline male & $\begin{array}{c}0.0160^{* * * *} \\
(0.00586)\end{array}$ & $\begin{array}{c}0.0198 * * * \\
(0.00530)\end{array}$ & $\begin{array}{l}0.0136^{*} \\
(0.00795)\end{array}$ & $\begin{array}{l}0.0160^{*} \\
(0.00855)\end{array}$ \\
\hline urban & $\begin{array}{c}0.0346^{* * * *} \\
(0.00974)\end{array}$ & $\begin{array}{c}0.0335^{* * * *} \\
(0.00851)\end{array}$ & $\begin{array}{c}0.0302^{* *} \\
(0.0123)\end{array}$ & $\begin{array}{c}0.0279 * * \\
(0.0108)\end{array}$ \\
\hline parim & $\begin{array}{c}0.0195 * * * \\
(0.00350)\end{array}$ & $\begin{array}{c}0.0224^{* * *} \\
(0.00298)\end{array}$ & $\begin{array}{c}0.0205^{* * *} \\
(0.00489)\end{array}$ & $\begin{array}{c}0.0239 * * * \\
(0.00407)\end{array}$ \\
\hline imfriend & $\begin{array}{c}0.0322^{* * *} \\
(0.00701)\end{array}$ & $\begin{array}{c}0.0299 * * * \\
(0.00762)\end{array}$ & $\begin{array}{c}0.0327^{* * *} \\
(0.00726)\end{array}$ & $\begin{array}{c}0.0302^{* * *} \\
(0.00830)\end{array}$ \\
\hline $\operatorname{lr}$ & $\begin{array}{c}-0.00919 * * * \\
(0.00307)\end{array}$ & $\begin{array}{c}-0.00789 * * \\
(0.00319)\end{array}$ & $\begin{array}{c}-0.00950^{* * *} \\
(0.00296)\end{array}$ & $\begin{array}{c}-0.00817^{* * *} \\
(0.00284)\end{array}$ \\
\hline highskill & $\begin{array}{c}0.0127^{* * * *} \\
(0.00346)\end{array}$ & $\begin{array}{c}0.0130 * * * \\
(0.00357)\end{array}$ & $\begin{array}{c}0.0160^{* *} \\
(0.00672)\end{array}$ & $\begin{array}{l}0.0142^{*} \\
(0.00758)\end{array}$ \\
\hline retired & $\begin{array}{c}-0.0492^{* * *} \\
(0.0125)\end{array}$ & $\begin{array}{c}-0.0484^{* * *} \\
(0.0121)\end{array}$ & $\begin{array}{c}-0.0416^{* * *} \\
(0.0100)\end{array}$ & $\begin{array}{c}-0.0413^{* * *} \\
(0.00996)\end{array}$ \\
\hline unemp & $\begin{array}{c}-0.0174 \\
(0.0247)\end{array}$ & $\begin{array}{r}-0.0192 \\
(0.0232)\end{array}$ & $\begin{array}{r}-0.0157 \\
(0.0413)\end{array}$ & $\begin{array}{r}-0.0207 \\
(0.0395)\end{array}$ \\
\hline paidemp & $\begin{array}{c}-0.00635 \\
(0.00913)\end{array}$ & $\begin{array}{c}-0.00935 \\
(0.00948)\end{array}$ & $\begin{array}{r}-0.0149 \\
(0.0123)\end{array}$ & $\begin{array}{r}-0.0187 \\
(0.0122)\end{array}$ \\
\hline Observations & 27477 & 27779 & 21719 & 21948 \\
\hline Pseudo $R^{2}$ & 0.0555 & 0.0603 & 0.0580 & 0.0628 \\
\hline
\end{tabular}

The sample includes only citizens of the majority ethnic group. Marginal effects holding all other variables at their mean value are shown with robust standard errors adjusted for clustering by country. The marginal effect, standard errors and statistical significance of the interaction terms are calculated using the stata program inteff.ado written by Edward Norton et al. *significant at $10 \% * *$ significant at $5 \% * *$ significant at $1 \%$. Country dummies are included in all estimations (coefficients not shown). Observations are weighted according to ESS guidelines. 


\section{Probit regression: Immigrants don't lower wages}

\begin{tabular}{|c|c|c|c|c|}
\hline COEFFICIENT & (1) & $(2)$ & (3) & $(4)$ \\
\hline educ & $\begin{array}{c}0.0157^{* * * *} \\
(0.00309)\end{array}$ & $\begin{array}{c}0.0214^{* * *} \\
(0.00527)\end{array}$ & $\begin{array}{c}0.0150^{* * * *} \\
(0.00323)\end{array}$ & $\begin{array}{c}0.0129 * * * \\
(0.00320)\end{array}$ \\
\hline nwsnp & & & $\begin{array}{c}0.0268 * * * \\
(0.00225)\end{array}$ & $\begin{array}{c}0.0259 \\
(0.0223)\end{array}$ \\
\hline ideallive & $\begin{array}{c}-0.133^{* * *} \\
(0.0233)\end{array}$ & & $\begin{array}{c}-0.116^{* * *} \\
(0.0109)\end{array}$ & \\
\hline sameculture & & $\begin{array}{c}-0.0536^{* * *} \\
(0.0128)\end{array}$ & & $\begin{array}{c}-0.0837^{* * *} * \\
(0.0107)\end{array}$ \\
\hline educ $^{*}$ ideallive & $\begin{array}{c}0.00146 \\
(0.001623)\end{array}$ & & & \\
\hline educ*sameculture & & $\begin{array}{c}-0.00261 * * * \\
(0.000973)\end{array}$ & & \\
\hline nwsnp $*^{\text {ideallive }}$ & & & $\begin{array}{c}-0.00130 * * * \\
(0.004613)\end{array}$ & \\
\hline nwsnp ${ }^{*}$ sameculture & & & & $\begin{array}{l}-0.00179 \\
(0.005988)\end{array}$ \\
\hline bthyr & $\begin{array}{c}-0.00146 * \\
(0.000800)\end{array}$ & $\begin{array}{c}-0.00163^{* *} \\
(0.000739)\end{array}$ & $\begin{array}{c}-0.00149 * * \\
(0.000585)\end{array}$ & $\begin{array}{c}-0.00168 * * * \\
(0.000540)\end{array}$ \\
\hline male & $\begin{array}{r}-0.0149 \\
(0.0102)\end{array}$ & $\begin{array}{c}-0.00861 \\
(0.0109)\end{array}$ & $\begin{array}{c}-0.0266^{* * *} \\
(0.0106)\end{array}$ & $\begin{array}{c}-0.0233^{* *} \\
(0.0119)\end{array}$ \\
\hline urban & $\begin{array}{c}-0.00323 \\
(0.0152)\end{array}$ & $\begin{array}{c}-0.00272 \\
(0.0148)\end{array}$ & $\begin{array}{c}0.00372 \\
(0.0137)\end{array}$ & $\begin{array}{c}0.00290 \\
(0.0133)\end{array}$ \\
\hline parim & $\begin{array}{c}0.00826 \\
(0.0142)\end{array}$ & $\begin{array}{l}0.0108 \\
(0.0145)\end{array}$ & $\begin{array}{c}0.000386 \\
(0.0159)\end{array}$ & $\begin{array}{c}0.00454 \\
(0.0161)\end{array}$ \\
\hline imfriend & $\begin{array}{c}0.0624 * * * \\
(0.00685)\end{array}$ & $\begin{array}{c}0.0556^{* * * *} \\
(0.00652)\end{array}$ & $\begin{array}{l}0.0617^{* * * *} \\
\quad(0.0109)\end{array}$ & $\begin{array}{c}0.0552^{* * *} \\
(0.00917)\end{array}$ \\
\hline $\operatorname{lr}$ & $\begin{array}{c}-0.00680^{* *} \\
(0.00271)\end{array}$ & $\begin{array}{c}-0.00309 \\
(0.00263)\end{array}$ & $\begin{array}{c}-0.00585^{*} \\
(0.00312)\end{array}$ & $\begin{array}{c}-0.00193 \\
(0.00337)\end{array}$ \\
\hline highskill & $\begin{array}{c}0.0512^{* * *} \\
(0.00938)\end{array}$ & $\begin{array}{c}0.0500^{* * * *} \\
(0.00990)\end{array}$ & $\begin{array}{l}0.0505^{* * * *} \\
(0.0115)\end{array}$ & $\begin{array}{l}0.0475 * * * \\
\quad(0.0116)\end{array}$ \\
\hline retired & $\begin{array}{c}0.000152 \\
(0.0158)\end{array}$ & $\begin{array}{c}0.00114 \\
(0.0156)\end{array}$ & $\begin{array}{c}-0.00622 \\
(0.0165)\end{array}$ & $\begin{array}{c}-0.00917 \\
(0.0169)\end{array}$ \\
\hline unemp & $\begin{array}{c}-0.0316 \\
(0.0321)\end{array}$ & $\begin{array}{r}-0.0331 \\
(0.0340)\end{array}$ & $\begin{array}{c}-0.0696^{*} \\
(0.0360)\end{array}$ & $\begin{array}{c}-0.0747^{* *} \\
(0.0373)\end{array}$ \\
\hline paidemp & $\begin{array}{c}0.0499 * * * \\
(0.00743)\end{array}$ & $\begin{array}{c}0.0459 * * * \\
\quad(0.00697)\end{array}$ & $\begin{array}{c}0.0589 * * * \\
(0.00809)\end{array}$ & $\begin{array}{c}0.0540^{* * * *} \\
(0.00823)\end{array}$ \\
\hline Observations & 27600 & 27919 & 21785 & 22036 \\
\hline Pseudo $R^{2}$ & 0.0803 & 0.0929 & 0.0823 & 0.0951 \\
\hline
\end{tabular}

The sample includes only citizens of the majority ethnic group. Marginal effects holding all other variables at their mean value are shown with robust standard errors adjusted for clustering by country. The marginal effect, standard errors and statistical significance of the interaction terms are calculated using the stata program inteff.ado written by Edward Norton et al. *significant at $10 \% * *$ significant at $5 \% * * *$ significant at $1 \%$. Country dummies are included in all estimations (coefficients not shown). Observations are weighted according to ESS guidelines. 


\section{Probit regression: Immigrants create jobs}

\begin{tabular}{|c|c|c|c|c|}
\hline COEFFICIENT & (1) & $(2)$ & (3) & $(4)$ \\
\hline educ & $\begin{array}{c}0.00805^{* * *} \\
(0.00211)\end{array}$ & $\begin{array}{c}0.0123^{* * *} \\
(0.00439)\end{array}$ & $\begin{array}{c}0.00658 * * * \\
(0.00103)\end{array}$ & $\begin{array}{c}0.00582^{* * *} \\
(0.000982)\end{array}$ \\
\hline nwsnp & & & $\begin{array}{c}0.0205^{* * * *} \\
(0.00769)\end{array}$ & $\begin{array}{c}0.0356 * * * \\
(0.00750)\end{array}$ \\
\hline ideallive & $\begin{array}{c}-0.0527^{*} \\
(0.0290)\end{array}$ & & $\begin{array}{c}-0.0878 * * * \\
(0.0187)\end{array}$ & \\
\hline sameculture & & $\begin{array}{l}-0.0177 \\
(0.0109)\end{array}$ & & $\begin{array}{c}-0.0377^{* * *} \\
(0.00714)\end{array}$ \\
\hline educ*ideallive & $\begin{array}{c}-0.00529^{* *} \\
(0.00269)\end{array}$ & & & \\
\hline educ*sameculture & & $\begin{array}{c}-0.00229^{* *} \\
(0.000982)\end{array}$ & & \\
\hline nwsnp*ideallive & & & $\begin{array}{l}-0.01817 \\
(0.014623)\end{array}$ & \\
\hline nwsnp ${ }^{*}$ sameculture & & & & $\begin{array}{c}-0.00708 * * * \\
(0.001925)\end{array}$ \\
\hline bthyr & $\begin{array}{c}-0.00158 * * * \\
(0.000368)\end{array}$ & $\begin{array}{c}-0.00156^{* * * *} \\
(0.000374)\end{array}$ & $\begin{array}{c}-0.00161 * * * \\
(0.000553)\end{array}$ & $\begin{array}{c}-0.00158 * * * \\
(0.000570)\end{array}$ \\
\hline male & $\begin{array}{c}0.0149 * * * \\
(0.00530)\end{array}$ & $\begin{array}{c}0.0180^{* * * *} \\
(0.00521)\end{array}$ & $\begin{array}{c}0.0188 * * \\
(0.00918)\end{array}$ & $\begin{array}{c}0.0197^{* *} \\
(0.00908)\end{array}$ \\
\hline urban & $\begin{array}{c}0.000368 \\
(0.0136)\end{array}$ & $\begin{array}{c}0.000859 \\
(0.0134)\end{array}$ & $\begin{array}{c}-0.00165 \\
(0.0157)\end{array}$ & $\begin{array}{c}-0.00193 \\
(0.0158)\end{array}$ \\
\hline parim & $\begin{array}{c}0.0327^{* * * *} \\
(0.0103)\end{array}$ & $\begin{array}{c}0.0347^{* * * *} \\
(0.0105)\end{array}$ & $\begin{array}{c}0.0309^{* *} \\
(0.0129)\end{array}$ & $\begin{array}{l}0.0341^{* * * *} \\
(0.0131)\end{array}$ \\
\hline imfriend & $\begin{array}{c}0.0525 * * * \\
(0.00827)\end{array}$ & $\begin{array}{c}0.0511^{* * * *} \\
(0.00802)\end{array}$ & $\begin{array}{l}0.0535 * * * \\
\quad(0.0112)\end{array}$ & $\begin{array}{l}0.0518^{* * * *} \\
(0.0104)\end{array}$ \\
\hline $\operatorname{lr}$ & $\begin{array}{c}-0.00543^{* * *} \\
(0.00193)\end{array}$ & $\begin{array}{c}-0.00466 * * * \\
(0.00163)\end{array}$ & $\begin{array}{c}-0.00397^{* *} \\
(0.00200)\end{array}$ & $\begin{array}{c}-0.00286 \\
(0.00174)\end{array}$ \\
\hline highskill & $\begin{array}{c}0.0279 * * * \\
(0.00898)\end{array}$ & $\begin{array}{c}0.0288^{* * * *} \\
(0.00915)\end{array}$ & $\begin{array}{c}0.0337^{* * * *} \\
(0.00999)\end{array}$ & $\begin{array}{l}0.0328^{* * * *} \\
(0.0100)\end{array}$ \\
\hline retired & $\begin{array}{c}-0.0219^{* * *} \\
(0.00753)\end{array}$ & $\begin{array}{c}-0.0196 * * \\
(0.00762)\end{array}$ & $\begin{array}{c}-0.0228 * * \\
(0.00994)\end{array}$ & $\begin{array}{c}-0.0239 * * \\
(0.00998)\end{array}$ \\
\hline unemp & $\begin{array}{r}-0.0363 \\
(0.0299)\end{array}$ & $\begin{array}{l}-0.0371 \\
(0.0265)\end{array}$ & $\begin{array}{r}-0.0230 \\
(0.0476)\end{array}$ & $\begin{array}{r}-0.0271 \\
(0.0448)\end{array}$ \\
\hline paidemp & $\begin{array}{c}-0.0164^{* *} \\
(0.00805)\end{array}$ & $\begin{array}{c}-0.0191^{* *} \\
(0.00796)\end{array}$ & $\begin{array}{c}-0.0209 * * \\
(0.00899)\end{array}$ & $\begin{array}{c}-0.0244^{* * *} \\
(0.00836)\end{array}$ \\
\hline Observations & 27857 & 28177 & 21966 & 22218 \\
\hline Pseudo $R^{2}$ & 0.0706 & 0.0706 & 0.0760 & 0.0760 \\
\hline
\end{tabular}

The sample includes only citizens of the majority ethnic group. Marginal effects holding all other variables at their mean value are shown with robust standard errors adjusted for clustering by country. The marginal effect, standard errors and statistical significance of the interaction terms are calculated using the stata program inteff.ado written by Edward Norton et al. *significant at $10 \% * *$ significant at $5 \% * * *$ significant at $1 \%$. Country dummies are included in all estimations (coefficients not shown). Observations are weighted according to ESS guidelines. 